\title{
BMJ Open Factors that influence career progression among postdoctoral clinical academics: a scoping review of the literature
}

\author{
Veronica Ranieri, ${ }^{1,2}$ Helen Barratt, ${ }^{2}$ Naomi Fulop, ${ }^{3}$ Geraint Rees ${ }^{4,5,6}$
}

To cite: Ranieri V, Barratt $\mathrm{H}$, Fulop N, et al. Factors that influence career progression among postdoctoral clinical academics: a scoping review of the literature. BMJ Open 2016;6:e013523. doi:10.1136/bmjopen-2016013523

- Prepublication history and additional material is available. To view please visit the journal (http://dx.doi.org/ 10.1136/bmjopen-2016013523).

Received 19 July 2016 Revised 27 September 2016 Accepted 29 September 2016

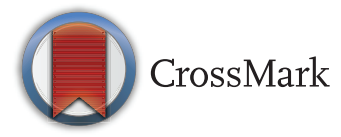

${ }^{1}$ Academic Careers Office, School of Life and Medical Sciences, University College London, London, UK 2Department of Applied Health Research, University College London, London, UK ${ }^{3}$ Health Care Organisation and Management,

Department of Applied Health Research, University College London, London, UK ${ }^{4}$ Faculty of Life Sciences, University College London, London, UK

${ }^{5}$ Department of Cognitive Neurology, University College London, London, UK

${ }^{6}$ Academic Careers Office, University College London, London, UK

Correspondence to Dr Veronica Ranieri; v.ranieri@ucl.ac.uk

\section{ABSTRACT}

Background: The future of academic medicine is uncertain. Concerns regarding the future availability of qualified and willing trainee clinical academics have been raised worldwide. Of significant concern is our failure to retain postdoctoral trainee clinical academics, who are likely to be our next generation of leaders in scientific discovery.

Objectives: To review the literature about factors that may influence postdoctoral career progression in early career clinical academics.

Design: This study employed a scoping review method. Three reviewers separately assessed whether the articles found fit the inclusion criteria.

Data sources: PubMed, Scopus, Web of Science and Google Scholar (1991-2015).

Article selection: The review encompassed a broad search of English language studies published anytime up to November 2015. All articles were eligible for inclusion, including research papers employing either quantitative or qualitative methods, as well as editorials and other summary articles.

Data extraction: Data extracted from included publications were charted according to author(s), sample population, study design, key findings, country of origin and year of publication.

Results: Our review identified 6 key influences: intrinsic motivation, work-life balance, inclusiveness, work environment, mentorship and availability of funding. It also detected significant gaps within the literature about these influences.

Conclusions: Three key steps are proposed to help support postdoctoral trainee clinical academics. These focus on ensuring that researchers feel encouraged in their workplace, involved in collaborative dialogue with key stakeholders and able to access reliable information regarding their chosen career pathway. Finally, we highlight recommendations for future research.

\section{INTRODUCTION}

Concerns about the future of academic medicine and, in particular, a potential shortage of trainee clinical academics have been expressed worldwide. ${ }^{1-3}$ A concern of
Strengths and limitations of this study

- In this article, we identify six factors that may influence career progression among postdoctoral clinical academic trainees.

- Our methodological approach enabled us to include a wide range of types of literature, from empirical studies to editorials.

- Including such a broad range of literature may have introduced a risk of bias.

- The literature we sourced was predominantly North American, so may be of limited relevance to clinical academic training in other countries.

particular significance is the failure to retain postdoctoral trainee clinical academics in clinical academic careers, once they have completed doctoral studies. ${ }^{4}$ This is noteworthy as the sustainability of academic medicine and future improvements in clinical practice are both contingent on a continuous pipeline of researchers. $^{5-7}$

In response to these concerns, a number of bodies around the world have invested a substantial amount of effort into improving the recruitment and retention of medical academic researchers. For instance, in 2003, an international group of medical academics, academic publishers and stakeholders came together to form a campaign to promote partnerships and global debate about how best to revitalise academic medicine. ${ }^{8}$ In England and Wales, this campaign preceded the roll out of a new Integrated Academic Training (IAT) programme for clinicians. The aim of this programme, overseen by the National Institute for Health Research, was to develop a clear pathway for aspiring medical academics. Trainees on this pathway receive protected research time that includes their medical training. ${ }^{9}$ This pathway consists of three key specialist academic training stages: a predoctoral Academic Clinical Fellowship, succeeded by a doctoral training fellowship and, finally, an Academic Clinical Lectureship. 9 
The IAT programme has yet to be formally evaluated. However, there are indications that only around a third of trainee doctors who complete a $\mathrm{PhD}$ within the UK progress to posts with clinical and academic responsibilities. ${ }^{10-12}$ These figures suggest that some postdoctoral trainee doctors experience either a change in their career preferences, having completed a $\mathrm{PhD}$, or difficulties in their career progression that prevent them from pursuing academic medicine.

Examining the available literature about the experiences of early career trainee clinical academics may help us understand the factors that influence this cohort's choice to pursue or discontinue a career in academia. The aim of this review is to describe the range of motivators, facilitators and barriers experienced by this group in their career development. For the purpose of this study, we use the term 'early career clinical academics' to describe medically qualified postdoctoral researchers who are in a clinical academic position typically within 5-7 years of obtaining their PhD qualification. From the factors identified in this scoping review, we make a number of proposals that could help support early career trainee clinical academics, as well as highlight areas where future research is warranted.

\section{METHODS}

\section{Scoping review}

The goal of this review was to map out the literature on the factors that influence career progression among postdoctoral clinical academics and identify areas within the research that need further clarification and emphasis. To achieve this, we undertook a scoping review as this method provides a way to synthesise a broad outline of the available evidence. ${ }^{13-16}$ Although systematic reviews may be viewed as the 'gold standard' when evaluating the evidence on a topic, they typically seek to answer specific questions, by summarising only the findings of studies with a predetermined design. ${ }^{13}$ In comparison, scoping reviews seek to describe the full range of literature relating to a broad area of research, including publications with a range of designs, such as editorials and systematic reviews, as well as quantitative or qualitative research articles. ${ }^{13}$

Arksey and O'Malley's ${ }^{13}$ initial framework for conducting a scoping review guided our method. This framework was chosen for its comprehensiveness and wide use in scoping reviews. This process consisted of identifying a clear research question; searching for and selecting relevant studies that aimed to answer our research question; and charting, summarising and reporting the findings of these studies. The framework does not include a quality assessment of included articles, as scoping reviews are designed to be rapid and broad in nature, as well as inclusive of all types of articles. ${ }^{14-16}$ Although later modifications have suggested that a quality assessment be included in scoping reviews, such assessment was not feasible for this review because no single tool exists for consistently appraising the breadth of the article types sought; qualitative, quantitative and opinion. ${ }^{14}{ }^{16}$ In line with recent enhancements to the framework, discussion between team members and separate reviewing of a proportion of abstracts and full-text papers were undertaken to ensure that relevant studies were included in the review. ${ }^{14-16}$ All potentially relevant articles references were uploaded onto referencing software where duplicates were accounted for a removed manually. (EndNote X5 [program]. X5 version: Thomson Reuters, 2016) Screening was conducted by VR, and a selection of included articles was reviewed by two other authors ( $\mathrm{HB}$ and $\mathrm{NF}$ ) to ensure that the topic they addressed adhered to our inclusion criteria.

\section{Search strategy}

This scoping review encompassed a broad search of English language studies published anytime up to November 2015. The following search engines were chosen as they covered a broad range of journals within health sciences: Web of Science, Scopus and PubMed. Google Scholar was used as an additional search engine to identify additional studies, including those present within the grey literature. Our search terms were ('academic medicine' OR 'clinical academia' OR 'clinician scientist' OR 'research physician') AND ('barriers' OR 'motivators' OR 'facilitators' OR 'predictors') AND ('career progression' OR 'career development') within the publication. Further information pertaining to our search terms is given in online supplementary appendix 1.

We included all English language publications that examined any influences experienced by early career clinical academics in any medical specialty. This included either the current perspectives of early career clinical academics or the retrospective viewpoints of researchers who progressed to a more senior position or left clinical academia following an early career post. In this study, early career clinical academics referred to individuals who had recently completed a $\mathrm{PhD}$ and in a junior research post typically lasting no more than 5-7 years since their completion date. We excluded publications if they did not include early career clinical academics within their sample or where none of the participants sampled held a PhD. The method adopted within each publication did not form part of our inclusion or exclusion criteria as studies using a range of methods were included. ${ }^{13}$

\section{Data extraction and synthesis of results}

We created a spreadsheet in Microsoft Excel to collect relevant data from each paper. Data extraction was performed by VR. Data were summarised qualitatively and quantitatively. To facilitate this, we extracted data regarding the following characteristics from all included studies: author(s), sample population, study design, key findings, country of origin and year of publication. 
Overarching themes were identified inductively from the study findings by VR and reviewed by all authors. A narrative summary was created for each theme.

\section{RESULTS}

Our database search produced 1105 potentially relevant articles. After assessing the eligibility of these by title and abstract, 890 articles were excluded as they did not meet our inclusion criteria. For example, excluded articles may have focused on different clinical academic professional groups, such as nurses, or on senior trainee clinical academics. The remaining 140 articles were then screened according to the same criteria on the basis of their full text. A total of 50 articles were included in the final review (see figure 1).

\section{Type of literature}

Included articles were predominantly American $(n=40)$. A further six articles were Canadian and the remaining four articles were British. The majority of included articles reported empirical research $(74 \%, \mathrm{n}=37)$. The remaining articles consisted of either editorials or commentaries. Publication dates spanned from 1991 to 2015 and papers were identified from 32 different journals. Information about the type of articles included in this review can be found in table 1. Six themes emerged on identifying and synthesising commonalities and contrasts found within the literature, as presented below.

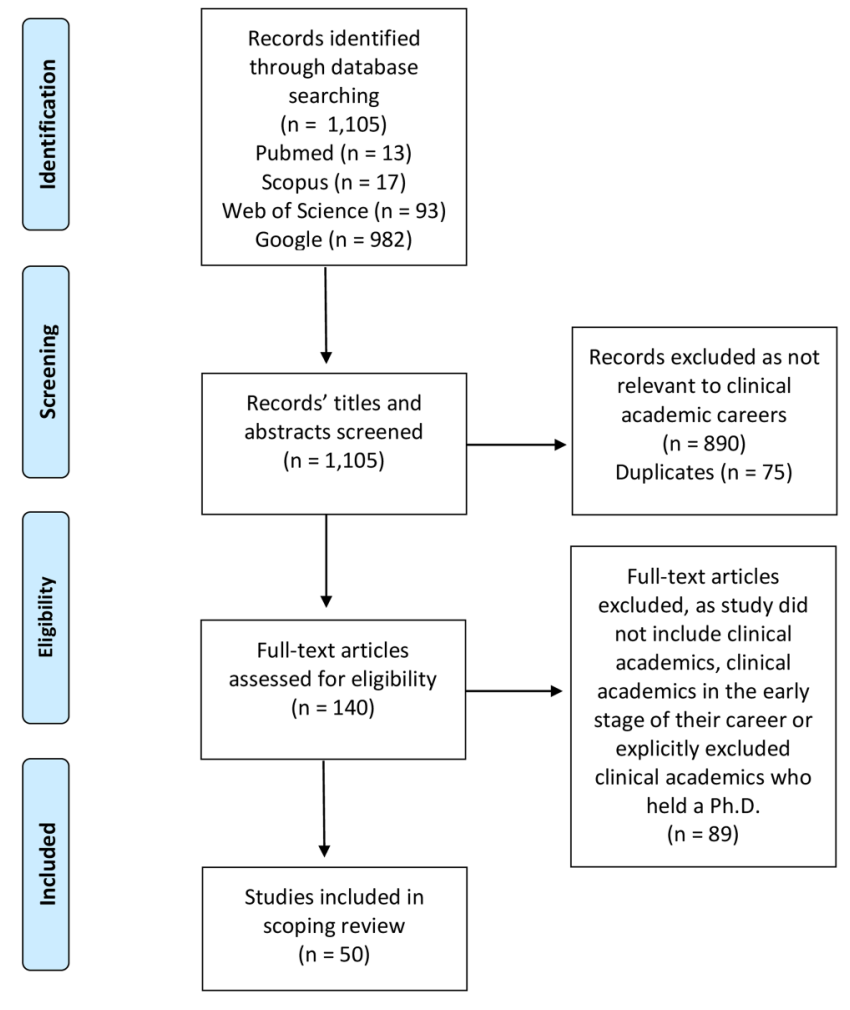

Figure 1 A PRISMA flow chart diagram of the scoping review process. ${ }^{17}$
Table 1 Types of publications reviewed $(\mathrm{N}=50)$

\begin{tabular}{|c|c|c|}
\hline $\begin{array}{l}\text { Types of } \\
\text { publications }\end{array}$ & $\begin{array}{l}\text { No of } \\
\text { publications } \\
\text { reviewed }\end{array}$ & Examples \\
\hline $\begin{array}{l}\text { Editorial or } \\
\text { commentary }\end{array}$ & 9 & $\begin{array}{l}\text { Kubiak et al (2012) } \\
\text { Kalia }(2003)^{19}\end{array}$ \\
\hline Empirical & 34 & $\begin{array}{l}\text { Bucklin et al }(2014)^{20} \\
\text { Steele et al }(2013)^{21} \\
\text { Kalfoglou et al. }(2002)^{22}\end{array}$ \\
\hline $\begin{array}{l}\text { Literature/ } \\
\text { systematic/ } \\
\text { workshop review }\end{array}$ & 6 & Straus et al. $(2006)^{23}$ \\
\hline Case study & 1 & Lander et al (2010) $)^{24}$ \\
\hline
\end{tabular}

\section{Theme 1: intrinsic motivation}

Intrinsic motivation, that is viewing academic medicine as rewarding and stimulating an inner interest or desire to discover, has been found to be an important factor in the literature. ${ }^{25}$ Early career trainee clinical academics perceived research to be highly valuable and pursued it despite uncertainty of career success. ${ }^{26} 27$ These individuals found their role intellectually stimulating and discovery exciting. ${ }^{28}$ Academic medicine, to those who were intrinsically motivated, afforded them with the opportunity to engage in different roles, for example teaching. ${ }^{18}{ }^{28}$ Following rejection from academic journals and funding bodies, early career researchers who were intrinsically motivated developed resilience and persevered in their careers. $^{29}$

\section{Theme 2: work-life balance}

Achieving a work-life balance in a time-constrained career is a challenge to many young academic physicians. ${ }^{30-32}$ Concerns regarding the ability to balance the already substantial workload of academic medicine with activities, such as childbearing and child rearing, are viewed as barriers to career development in academic medicine. Such barriers, though significant, were potentially overcome by financial stability and positive personal and social conditions in the postdoctoral researcher's life. ${ }^{30}$ When the option of part-time work to meet the needs of those with more challenging worklife scenarios was unsupported by senior colleagues, a larger proportion of junior clinical academics elected to leave academic medicine. ${ }^{34}$

\section{Theme 3: inclusiveness}

A third influence which emerged was career discrimination based on gender or race. However, gender-based studies of career advancement in academic medicine have highlighted some contradictory issues. ${ }^{35-37}$ Recent evidence indicates that there is no difference between genders in terms of receipt of governmental funding, number of publications or h-index at an early career stage. ${ }^{36} 38$ However, earlier studies suggested that women were awarded only $31-47 \%$ of US National 
Institutes of Health (NIH) career development awards between 1997 and 2008 (K08/K23). ${ }^{39}$ Furthermore, men outnumber women in junior clinical academic positions with over half of assistant professorships being held by men. 3940

Nevertheless, female early career researchers perceive gender-based discrimination as a significant barrier to career development. ${ }^{41}$ Desire to leave clinical academia was much greater in women than men who were in a junior faculty position. ${ }^{42}$ 43 $\mathrm{A}$ former junior female faculty identified a number of factors that led them to leave academic medicine. Both a shortage of female role models that championed balancing work and family responsibilities (and inspired others to do the same) and low remuneration discouraged female physicians from pursuing an academic career. ${ }^{44-47}$ Female clinician scientists distinctly expressed doubt regarding their ability to advance and successfully integrate family life with a career in academic medicine. ${ }^{19}{ }^{48}$ In addition, a lack of role models created an unwelcoming environment for ethnic minority staff and led to an environment in which staff felt that they did not belong and left their employment. ${ }^{49} 50$

\section{Theme 4: work environment}

Allied to influences present within the individual, were influences experienced externally. Three principal themes related to the individual's environment emerged from the literature: type of work environment; access to mentoring and availability of funding. Early career trainee clinical academics expressed a desire for an inclusive, respectful and flexible environment that promoted creativity and academic freedom. ${ }^{20} 5152$ A junior faculty valued institutions that were committed to their career development. They were discouraged by institutional failure to formally recognise their dedication to teaching and ambiguity regarding their pathway to promotion. ${ }^{20} 275354$ Pressure to prioritise clinical duties over research and teaching was frequently cited as a negative aspect of early career clinical academics' working environment. ${ }^{55}$ Those who left academic medicine described their research institution as unwelcoming and individualistically competitive. ${ }^{44} 51$ Feeling isolated from peers, sensing a lack of support and fearing retribution for open communication deterred junior trainee clinical academics from pursuing academic medicine. ${ }^{20} 51$ Furthermore, returning to a research unfriendly residency following completion of a $\mathrm{PhD}$ and being appointed to a temporary research rather than tenure track position in the USA were linked to attrition from academic medicine. ${ }^{20} 2756$

\section{Theme 5: mentorship}

The fifth theme we identified is mentorship, which studies suggest is often experienced to differing degrees in the workplace. Early career researchers emphasised how important a research supervisor was to their academic career advancement. ${ }^{21} 5758$ Those who were based in an academic setting that nurtured supportive mentorship and positive role modelling tended to pursue academic medicine with greater career satisfaction and confidence. $^{59-61}$ Optimal mentorship was marked by altruistic guidance and clarity from supervisors who encouraged junior faculty. ${ }^{18}{ }^{52}$ Effective mentors provided moral and institutional support to aid in their mentee's personal and career development. ${ }^{236062}$ Such mentorship was found to be particularly critical when trying to secure independent funding and in building resilience in the face of grant or publication rejection. ${ }^{29} 33$ Those who successfully attained a postdoctoral post attributed some of their success to mentorship that increased their level of trust in their own capabilities, promoted greater independence of thought within research and desire to remain within clinical academia. ${ }^{63}$ Nevertheless, to some, identifying a suitable and available mentor to guide, advise and critique their work was a significant barrier and led to attrition. ${ }^{18} 2764$ Effective mentoring was undermined by relational shortcomings such as poor working alliance and ineffective communication and functional shortcomings linked to time constraints and lack of incentive from the mentee. ${ }^{60} 62$

\section{Theme 6: availability of funding}

The availability of funding is the final key theme we identified in the literature as being crucial to early career clinical academics' career progression. ${ }^{65}$ Difficulties in acquiring research grant funding that allowed for protected time for research were cited as a barrier to career progression in early career researchers. ${ }^{22} 6667$ Attaining funding was limited by a perceived loss or scarcity of funding sources. ${ }^{52}$ This, in turn, was attributed to a decrease in governmental investment in research and competition with full-time researchers for the same grants in Northern America. ${ }^{245}$ Furthermore, financial pressures such as concerns regarding debt management and pay equity between clinical and academic faculties were perceived as demotivating. ${ }^{18} 2464$

\section{DISCUSSION}

This scoping review was conducted to inform the debate about the sustainability of academic medicine. We identified six key themes in the literature, which may influence academic career progression among early career clinical academics. These themes include the role of intrinsic motivation in the development of a clinical academic career, the difficulties inherent in achieving a work-life balance in academic medicine and perceived differences in career progression according to demographic factors such as gender and ethnicity. Our review also highlights the positive influence of supportive mentorship on career advancement and the effect that the workplace environment may have on early career trainee clinical academics' motivation to remain in academia. Finally, one of the most frequently cited themes was the availability of funding and the negative 
implications of limited access to such funding for an early career clinical academic's career progression. In line with our search strategy, each influence can be regarded as either a facilitator or a barrier to career progression.

This scoping review is novel in that it collates and synthesises the evidence pertaining to factors or influences affecting clinical doctoral trainees' academic career decisions following the completion of their doctoral studies. Unlike previous reviews, it distinctly emphasises the completion of a doctorate as a focal entry point into a clinical academic career and focuses on the experiences of those who recently completed this milestone. ${ }^{23}$ Its key strength is that it describes a wide range of literature, ranging from editorials to systematic reviews that examine pertinent aspects or influences, to produce an overall narrative of the experiences of early career trainee clinical academics. While many of the research articles we found tended to provide detailed descriptions of specific influences experienced by our target population, they often failed to provide a bigger picture. Editorials, conversely, were more adept at doing so but, we found, were often not cited in research articles. These, however, carry a risk of bias as they are based on opinion rather than science. Recent articles have urged researchers to perform a quality assessment of the included literature in an effort to improve the robustness of scoping reviews. ${ }^{14}$ 1668 As this review included a mixture of quantitative, qualitative and editorials, there was no single quality assessment measure available to us that embraced the wide range of research designs included. Nevertheless, this exercise provided us with an enriched narrative of what is known on the topic. Furthermore, this review provides details such as the sample size and study location of the included articles, so that readers can determine the generalisability of the studies.

The literature we found was important in revealing the influences experienced by trainees. However, some of the studies explored the views of junior and senior researchers and did not distinguish between the views of these two groups. ${ }^{18} 51526263$ These studies may, therefore, not wholly represent the views of junior researchers. Second, some of the included studies did not specify whether all early career trainee clinical academics held a PhD. ${ }^{20} 2126293059$ In searching specifically for published data relating to our target group, it is possible that we may have overlooked influences that are likely to affect early career clinical academics, but are only reported in the broader career literature. Additionally, in limiting our search to our specific search terms, we may have restricted the articles produced by our search, thus limiting our range of possible themes.

The themes identified from this scoping review are unlikely to apply to academic medicine alone. For example, gender inequality features in many facets of academia and, in the UK, has led to the Athena SWAN Charter, a charter designed to encourage the participation of women in higher education and research. ${ }^{69}$ However, highlighting and synthesising the findings of international studies may only partially shed light on the experiences of early career clinical academics in the UK. Nevertheless, drawing on our findings, we propose that there are three key actions we can take to help encourage our early career clinical academics. ${ }^{12}$ Ensuring that junior researchers feel integrated and supported in their work environment, for example, by improving mentoring or supervisory practices, may act as a significant first step. Including early career clinical academics in a collaborative dialogue with key stakeholders, such as universities and sponsoring bodies, may help this group feel involved in career decisions that affect them. Finally, collecting routine data on clinical academic training pathways and trainees' experiences from these universities and sponsoring bodies and regularly releasing such data to those who need it may help inform the format of future academic training for clinical researchers.

Our review highlights a number of significant gaps in our current knowledge. The literature we reviewed tended to focus on the barriers that impeded career advancement. Much less was found on the motivations to continue to pursue clinical academia. For example, although we are now familiar with the positive effects of supervisory research mentorship, we do not yet know whether different forms of mentoring affect postdoctoral trainee clinical academics' career progression. On a practical level, the next step in advancing our knowledge of the experiences of this cohort is to examine the effect of the above themes on career progression according to career grade and discipline. In doing so, we need to also ask postdoctoral trainee clinical academics about their perceptions of accessing funding and satisfaction with supervisory (or other) mentorship. Within the UK, this examination should include a formal evaluation of the IAT programme. This exercise should assess whether our junior clinical researchers perceive a clear and unobstructed trajectory into academic medicine.

Although there is limited information available to describe the experiences of trainee clinical academics, a range of theories have been set out in the broader career development literature to account for why individuals may remain in a chosen career pathway. We argue that embracing a theoretical stance when examining these perspectives may provide a better understanding of how these themes impact early career clinical academics. Incorporating such theory may help us to objectively recognise the underlying mechanisms at play in this group's career decisions. ${ }^{70}$ It may also help us sculpt our proposals and methods of intervention accordingly. However, no theory alone could sufficiently account for all the influences that trainee clinical academics may experience in their careers. Instead, we propose applying a systems theory framework that integrates a number of influencing factors identified in prominent theories of career development and present these as one metatheory. ${ }^{71}$ 
Using this framework, such influences are divided according to whether they are present within the individual (for instance, beliefs regarding one's ability to succeed in a chosen career path, as outlined in selfefficacy theory and social cognitive career theory), within the individual's immediate social system (eg, perceptions of disparity within the workplace that may lead to disengagement, as proposed by the psychological contract theory) or within the greater environment (such as the influence of globalisation, geography, socioeconomics and employment opportunities)..$^{72-78}$

\section{CONCLUSION}

To conclude, this scoping review provides a synthesis of the influences that are experienced by early career clinical academics in their academic career progression internationally. In line with the themes found, three key steps are proposed to help support this group. In light of changes to clinical academic training in the UK, a key next step must be to evaluate whether junior trainee clinical academics perceive a clear and unobstructed future trajectory into academic medicine.

Contributors All authors made substantial contributions to the conception, design of the work and the interpretation of data for the work. VR screened for relevant abstracts and articles. VR, HB and NF reviewed abstracts and full-text articles. VR and HB drafted the initial manuscripts. All authors revised the drafts critically for important intellectual content, approved the final version to be published and agree to be accountable for all aspects of the work in ensuring that questions related to the accuracy or integrity of any part of the work are appropriately investigated and resolved.

Funding This research/study/project was funded by the National Institute for Health Research University College London Hospitals Biomedical Research Centre. This research was also supported by the National Institute for Health Research (NIHR) Collaboration for Leadership in Applied Health Research and Care North Thames at Barts Health NHS Trust.

Disclaimer The views expressed in this publication are those of the authors and not necessarily those of the NHS, the National Institute for Health Research or the Department of Health.

Competing interests None declared.

Provenance and peer review Not commissioned; externally peer reviewed.

Data sharing statement No additional data are available.

Open Access This is an Open Access article distributed in accordance with the terms of the Creative Commons Attribution (CC BY 4.0) license, which permits others to distribute, remix, adapt and build upon this work, for commercial use, provided the original work is properly cited. See: http:// creativecommons.org/licenses/by/4.0/

\section{REFERENCES}

1. Stewart PM. Academic medicine: a faltering engine-action is needed to respond to growing need and opportunities. BMJ 2002;324:437-8.

2. Clark J, Tugwell P. Who cares about academic medicine? BMJ 2004;329:751-2.

3. Pololi LH, Krupat E, Civian JT, et al. Why are a quarter of faculty considering leaving academic medicine? A study of their perceptions of institutional culture and intentions to leave at 26 representative U.S. medical schools. Acad Med 2012:87:859-69.

4. Aronson JK. How to attract, retain and nurture young academic clinicians. J R Soc Med 2011;104:6-14.

5. Bell J. Resuscitating clinical research in the United Kingdom. BMJ 2003;327:1041-3.
6. The Academy of Medical Sciences. Supporting tomorrow's leaders today. The Academy of Medical Sciences' mentoring scheme for postdoctoral clinical academics. London: The Academy of Medical Sciences, 2012

7. Vollers JM. What is the real academic medicine crisis? Acad Phys Sci 2006;Apr:8-9.

8. Wilkinson D. ICRAM (the International Campaign to Revitalise Academic Medicine): agenda setting. BMJ 2004;329:787-9.

9. Funston $\mathrm{G}$, Cera $\mathrm{C}$, Kirkham D, et al. The road to a clinical academic career. BMJ Careers 2015. http://careers.bmj.com/careers/advice/ the_road_to_a_clinical_academic_career

10. Wellcome Trust. Wellcome trust clinical career tracker results of wave 3 (2013): Summary report. London: Wellcome Trust, 2014.

11. Cancer Research UK. Clinical careers review. London: Cancer Research UK, 2015.

12. Ranieri $\mathrm{V}$, Barratt $\mathrm{H}$, Fulop $\mathrm{N}$, et al. Clinical academics' postdoctoral career development. BMJ 2015;351:h6945.

13. Arksey H, O'Malley L. Scoping studies: towards a methodological framework. Int J Soc Res Methodol 2005;8:19-32.

14. Colquhoun $\mathrm{HL}$, Levac D, O'Brien KK, et al. Scoping reviews: time for clarity in definition, methods, and reporting. J Clin Epidemiol 2014;67:1291-4.

15. Levac D, Colquhoun H, O'Brien KK. Scoping studies: advancing the methodology. Implement Sci 2010;5:69.

16. Daudt HM, van Mossel C, Scott SJ. Enhancing the scoping study methodology: a large, inter-professional team's experience with Arksey and O'Malley's framework. BMC Med Res Methodol 2013;13:48.

17. Moher $\mathrm{D}$, Liberati $\mathrm{A}$, Tetzlaff $\mathrm{J}$, et al. Preferred reporting items for systematic reviews and meta-analyses: the PRISMA statement. BMJ 2009;339:b2535.

18. Kubiak NT, Guidot DM, Trimm RF, et al. Recruitment and retention in academic medicine-what junior faculty and trainees want department chairs to know. Am J Med Sci 2012;344:24-7.

19. Kalia LV. Barriers to women clinician-scientists: a trainee's perspective. Clin Invest Med 2003;26:15-16.

20. Bucklin BA, Valley M, Welch C, et al. Predictors of early faculty attrition at one academic medical center. BMC Med Educ 2014;14:27.

21. Steele MM, Fisman S, Davidson B. Mentoring and role models in recruitment and retention: a study of junior medical faculty perceptions. Med Teach 2013;35:e1130-8.

22. Kalfoglou AL, Sung NS. What inspires clinical research trainees and keeps them on the path? J Investig Med 2002;50:408-11.

23. Straus SE, Straus C, Tzanetos K. International campaign to revitalise academic medicine. Career choice in academic medicine: systematic review. J Gen Intern Med 2006;21:1222-9.

24. Lander B, Hanley GE, Atkinson-Grosjean J. Clinician-scientists in Canada: barriers to career entry and progress. PLOS ONE 2010;5: e13168.

25. Isaac C, Byars-Winston A, McSorley R, et al. A qualitative study of work-life choices in academic internal medicine. Adv Health Sci Educ Theory Pract 2014:19:29-41.

26. Sanders AB, Fulginiti JV, Witzke DB, et al. Characteristics influencing career decisions of academic and nonacademic emergency physicians. Ann Emerg Med 1994;23:81-7.

27. Weinert CR, Billings J, Ryan R, et al. Academic and career development of pulmonary and critical care physician-scientists. Am J Respir Crit Care Med 2006;173:23-31.

28. Osborn EH, Ernster VL, Martin JB. Women's attitudes toward careers in academic medicine at the University of California, San Francisco. Acad Med 1992;67:59-62.

29. DeCastro R, Sambuco D, Ubel PA, et al. Batting 300 is good: perspectives of faculty researchers and their mentors on rejection, resilience, and persistence in academic medical careers. Acad Med 2013;88:497-504.

30. Strong EA, De Castro R, Sambuco D, et al. Work-life balance in academic medicine: narratives of physician-researchers and thei mentors. J Gen Intern Med 2013;28:1596-603.

31. Donowitz M, Germino G, Cominelli F, et al. The attrition of young physician-scientists: problems and potential solutions. Gastroenterology 2007;132:477-80.

32. Cochran A, Elder WB, Crandall M, et al. Barriers to advancement in academic surgery: views of senior residents and early career faculty. Am J Surg 2013;206:661-6.

33. Khadaroo RG, Rotstein OD. Are clinician-scientists an endangered species? Barriers to clinician-scientist training. Clin Invest Med 2002:25:260-1.

34. Harrison RA, Gregg JL. A time for change: an exploration of attitudes toward part-time work in academia among women internists and their division chiefs. Acad Med 2009;84:80-6. 
35. Holliday EB, Jagsi R, Wilson LD, et al. Gender differences in publication productivity, academic position, career duration, and funding among U.S. academic radiation oncology faculty. Acad Med 2014;8:767-73.

36. Jagsi R, DeCastro R, Griffith KA, et al. Similarities and differences in the career trajectories of male and female career development award recipients. Acad Med 2011;86:1415-21.

37. Nattinger AB. Promoting the career development of women in academic medicine. Arch Intern Med 2007;167:323-4.

38. Jagsi R, Motomura AR, Griffith KA, et al. Sex differences in attainment of independent funding by career development awardees. Ann Intern Med 2009;151:804-11.

39. Kalyani RR, Yeh HC, Clark JM, et al. Sex differences among career development awardees in the attainment of independent research funding in a department of medicine. J Womens Health (Larchmt) 2015;24:933-9.

40. Speck RM, Sammel MD, Troxel AB, et al. Factors impacting the departure rates of female and male junior medical school faculty: evidence from a longitudinal analysis. J Womens Health (Larchmt) 2012;21:1059-65.

41. Cochran A, Hauschild T, Elder WB, et al. Perceived gender-based barriers to careers in academic surgery. Am J Surg 2013;206:263-8.

42. Schroen AT, Brownstein MR, Sheldon GF. Women in academic general surgery. Acad Med 2004;79:310-18.

43. Bellini LM, Abbuhl S, Grisso JA, et al. Stresses and workplace resources for academic junior faculty: track and gender comparisons. Acad Med 2001;76(Suppl 10):S62-4.

44. Levine RB, Lin F, Kern DE, et al. Stories from early-career women physicians who have left academic medicine: a qualitative study at a single institution. Acad Med 2011;86:752-8.

45. Cropsey KL, Masho SW, Shiang R, et al. Why do faculty leave? Reasons for attrition of women and minority faculty from a medical school: four-year results. $J$ Womens Health (Larchmt) 2008;17:1111-18.

46. Carr PL, Szalacha L, Barnett R, et al. A 'ton of feathers': gender discrimination in academic medical careers and how to manage it. $J$ Womens Health (Larchmt) 2003;12:1009-18.

47. Levinson W, Kaufman K, Clark B, et al. Mentors and role models for women in academic medicine. West $J$ Med 1991;154:423.

48. Fassiotto M, Hamel EO, Ku M, et al. Women in academic medicine: measuring stereotype threat among junior faculty. J Womens Health (Larchmt) 2016;25:292-8.

49. Price EG, Gozu A, Kern DE, et al. The role of cultural diversity climate in recruitment, promotion, and retention of faculty in academic medicine. J Gen Intern Med 2005;20:565-71.

50. Cora-Bramble D, Zhang K, Castillo-Page L. Minority faculty members' resilience and academic productivity: are they related? Acad Med 2010;85:1492-8.

51. Pololi L, Conrad P, Knight S, et al. A study of the relational aspects of the culture of academic medicine. Acad Med 2009;84:106-14.

52. Adams A, Lester $\mathrm{H}$, Reeve J, et al. Investigating the sustainability of careers in academic primary care in the United Kingdom. Prim Health Care Res Dev 2014;15:331-5

53. Wai PY, Dandar V, Radosevich DM, et al. Engagement, workplace satisfaction, and retention of surgical specialists in academic medicine in the United States. J Am Coll Surg 2014;219:31-42.

54. Sarfaty S, Kolb D, Barnett R, et al. Negotiation in academic medicine: a necessary career skill. $J$ Womens Health (Larchmt) 2007;16:235-44.
55. Rosier RN. Institutional barriers to the orthopaedic clinician-scientist. Clin Orthop Relat Res 2006;449:159-64.

56. Culican SM, Rupp JD, Margolis TP. Retaining clinician-scientists: nature versus nurture. Invest Ophthalmol Vis Sci 2014;55:3219-22.

57. Lewis RJ. Some thoughts regarding gender issues in the mentoring of future academicians. Acad Emerg Med 2003;10:59-61.

58. Kashiwagi DT, Varkey $P$, Cook DA. Mentoring programs for physicians in academic medicine: a systematic review. Acad Med 2013;88:1029-37.

59. Horn L, Koehler E, Gilbert J, et al. Factors associated with the career choices of hematology and medical oncology fellows trained at academic institutions in the United States. J Clin Oncol 2011;29:3932-8.

60. Flexman AM, Gelb AW. Mentorship in anesthesia. Curr Opin Anaesthesiol 2011;24:676-81.

61. Straus SE, Johnson MO, Marquez C, et al. Characteristics of successful and failed mentoring relationships: a qualitative study across two academic health centers. Acad Med 2013;88:82-9.

62. Sambunjak D, Straus SE, Marusic A. Mentoring in academic medicine: a systematic review. JAMA 2006;296:1103-15.

63. Iversen AC, Eady NA, Wessely SC. The role of mentoring in academic career progression: a cross-sectional survey of the academy of medical sciences mentoring scheme. $J R$ Soc Med 2014;107:308-17.

64. Smesny AL, Williams JS, Brazeau GA, et al. Barriers to scholarship in dentistry, medicine, nursing, and pharmacy practice faculty. Am J Pharm Educ 2007;71:91.

65. Stewart PM, Bryan S, Dukes $P$, et al. What happens to clinical training fellows? A retrospective study of the 20 years outcome of a Medical Research Council UK cohort. BMJ Open 2012;2:e001792.

66. Lank PM. A fellow's perspective on beginning a satisfying career in academic medical toxicology. J Med Toxicol 2013;9:123-4.

67. Choi AM, Reynolds HY, Colombini-Hatch S, et al. NHLBI workshop: respiratory medicine-related research training for adult and pediatric fellows. Lung 2009;187:347-66.

68. Tricco $A C$, Lillie $\mathrm{E}$, Zarin $\mathrm{W}$, et al. A scoping review on the conduct and reporting of scoping reviews. BMC Medical Research Methodology 2016;16:15

69. Equality Challenge Unit. Athena SWAN Charter, 22 June. 2005.

70. Davidoff F, Dixon-Woods M, Leviton L, et al. Demystifying theory and its use in improvement. BMJ Qual Saf 2015;24:228-38.

71. Patton WM, McMahon M. Career development and systems theory. Connecting theory and practice. 3rd edn. Rotterdam: Sense Publishers, 2006.

72. Bandura A. Self-efficacy: toward a unifying theory of behavioral change. Psychol Rev 1977;84:191-215.

73. Brown S, Lent R. A social cognitive framework for career choice counseling. Career Dev Q 1996;44:355-67.

74. Lent RW, Brown SD. Social cognitive model of career self-management: toward a unifying view of adaptive career behavior across the life span. J Couns Psychol 2013;60:557-68.

75. Holland JL. Making vocational choices: a theory of vocational personalities and work environments. 3rd edn. Odessa, FL: Psychological Assessment Resources, 1997.

76. Reardon RC, Lenz JG. Holland's theory and career assessment. $J$ Vocational Behav 1999;55:102-13.

77. McCrae RR, John OP. An introduction to the five-factor model and its applications. J Pers 1992;60:175-215.

78. Rousseau DM. Psychological and implied contracts in organizations. Employee Responsibilities Rights J 1989;2:121-39. 